American Journal of Applied Sciences 9 (10): 1553-1560, 2012

ISSN 1546-9239

(C) 2012 Science Publication

\title{
Asthma Severity and Environmental Health Risk Factor among Asthmatic Primary School Children in the Selected Areas
}

\author{
${ }^{1,2}$ Junaidah Zakaria, ${ }^{3}$ Lye Munn Sann and ${ }^{1}$ Zailina Hashim \\ ${ }^{1}$ Department of Environmental and Occupational Health, \\ Faculty of Medicine and Health Science, \\ Universiti Putra Malaysia, 43400 Serdang, Selangor Darul Ehsan, Malaysia \\ ${ }^{2}$ Faculty of Science and industrial Technology, \\ University Pahang Malaysia, Lebuhraya Tun Razak, 26300 Kuantan, Pahang., Malaysia \\ ${ }^{3}$ Department of Community Health, Faculty of Medicine and Health Science \\ Universiti Putra Malaysia, 43400 Serdang, Selangor Darul Ehsan, Malaysia
}

\begin{abstract}
Problem statement: The purpose of this study was to assess the severity of asthma and associated risk factors among asthmatic primary school children in the selected urban, industrial and rural areas of Selangor and Kuala Lumpur. Approach: A total of 207 respondents were involved in this study, in which 87 were children from the urban areas, 67 children were from the industrial areas and another 53 children were from rural areas. The selection of respondents was based on purposive sampling method, where only asthmatic children who had been diagnosed by physicians were involved. Health records of the children were obtained from the school administration office. Respondents were children from Standard 2 to Standard 5, with informed consent from their parents. A modified ISAAC Questionnaire translated into the Malay language was administered to the children and then completed by the parents. Peak Expiratory Flow (PEF) readings were measured using a peak flow meter Mini Weight Model AFS CE 0120 on Monday, Wednesday and Friday before and after the school hour. Continuous ambient air pollutants $\left(\mathrm{PM}_{10}, \mathrm{CO}, \mathrm{SO}_{2}\right.$ and $\left.\mathrm{NO}_{2}\right)$ levels were obtained from the Department of Environment. Results: Results showed significant influence of PEF reading before and days in the week, on the PEF reading after school among respondents. The severity of asthma among respondents was classified according to the PEF variability, day and night symptoms as well as the respiratory scores. Most of the children had mild and moderate asthma. Statistics showed that $\mathrm{PM}_{10}$ and allergy to pollen significantly influenced the asthma severity among respondents. Conclusion: The air pollutants in term of $\mathrm{PM}_{10}$ which may contain pollen were higher in the urban and industrial areas. This study provided a confirmatory evidence that the asthmatic children who live in urban and industrial areas have greater risk of developing severe asthma.
\end{abstract}

Key words: Asthma, school children, air pollutants, peak expiratory flow and severity

\section{INTRODUCTION}

Asthma is a chronic obstructive lung disease caused by the inflammation and increase reaction of the airways to various triggers. This condition is due to the inflammation of the air passages in the lungs and subsequently affects the sensitivity of the nerve endings in the airways and easily become irritated. In susceptible individuals, this inflammation causes recurrent episodes of wheezing, breathlessness, chest tightness and cough particularly at night and early in the morning (Johnston and Holgate, 2008; Haitchi et al., 2004; Bosquet et al., 2000).
In Malaysia, there is a very limited number of studies that relate air pollution to the heath impacts. Recent studies in this country have examined the possible health effects of the 1997 forest fires. Asthma cases increased from only 912 in June to more than 5000 in September. Apart from that, the total number of acute respiratory infection cases increased from about 6000 cases to more than 30,000 during the same period (Rafia et al., 2003). Effects were found to be greatest in children, the elderly and people with pre-existing respiratory problem. A study conducted by Nasir et al. (2000), suggested that in the 1997 haze episode the total

Corresponding Author: Zailina Hashim, Department of Environmental and Occupational Health,

Faculty of Medicine and Health Science, University Putra Malaysia, 43400 Serdang,

Selangor Darul Ehsan, Malaysia Tel: 603-89472397 
health effects were estimated to include 285,227 asthma attacks and 118,804 cases of bronchitis in children. Local study found that $13.8 \%$ of primary school children in Kuala Lumpur are asthmatic (Omar, 1990). This study was intended to investigate the association between pollutants exposure and the severity of asthma among primary school children.

\section{MATERIALS AND METHODS}

Study design and location: This is a cross sectional comparative study conducted in the Klang Valley. Schools from Cheras and Petaling Jaya were selected to represent the urban areas. Schools from Klang represented the industrial area and lastly schools from Hulu Langat (Beranang) and Kuala Langat (Morib and Banting) represented the rural areas.

Study sample: Study sample made up of the primary school children from the age between 8-11 years old with asthma, at the selected schools. There were three groups of school children studied namely the urban, industrial and rural group. A list of schools were obtained from the Ministry of Education. Schools were selected within 1 $\mathrm{km}$ radius of the air monitoring station's location in the urban and industrial and rural areas. Another criteria was that only the Grade A were included in the study. According to the Ministry of Education, in urban areas, a Grade A school has more than 1000 students, whereas in the rural areas, a Grade A has only more than 300 students enrolled in the rural areas.

Inclusion Criteria for asthmatic children: Students from all selected schools must fulfill these inclusive criteria:

- Had been diagnosed as asthma according to the school health record book

- Ages between 8 to 11 years old

- Malaysian

Questionnaire: A standardized set of questionnaire from the International Study of Asthma and Allergies in Childhood (ISAAC) questionnaire with some modifications was used in the study. The questionnaire comprises questions on asthma, allergies and respiratory symptoms. The questionnaire was translated from English to Malay. Study conducted by local researcher revealed that the translated ISAAC questionnaire was more reliable since the Kappa values of $>0.4$ were obtained (Norzila et al., 2000). Pretest of the questionnaires was also carried out among the urban and rural parents to ensure that the questionnaires were easily comprehensible especially for the rural respondents. Results from the pre-test were used to improve some of the questions for better understanding.

Peak expiratory flow reading: Peak expiratory flow readings were taken before and after school on Monday, Wednesday and Friday. Instruction was given to all children on how to blow into the peak flow meter. They were asked to stand up straight and hold the peak flow meter horizontally. The mouthpiece was held between the teeth and over the tongue, with lips sealed around it. The children were then instructed to blow hard and as quickly as possible. The readings were then recorded. PEF variability was calculated as follows:

$$
\frac{\text { Highest PEF }- \text { Lowest PEF }}{\text { Highest PEF }} \times 100
$$

Formula for calculating the PEF variability (PérezYarza et al., 2006).

Classification of asthma: The most accepted classifications of asthma severity were recommended by the National Heart, Lung and Blood Institute's (NHLBI) under the Asthma Education and Prevention Program (NAEPP) Expert Panel Report 2. Three variables are taken into consideration in classifying asthma namely daytime symptoms, nighttime symptoms and PEF variability.

From these three variables, the abnormalities were graded into four categories according to the worst individual variable. For instance, if a person had severe persistent daytime symptoms but has nighttime less than twice per week and normal lung functions, the overall asthma categorization would be as severe persistent. In this study, the classification of asthma was categorized into four categories, which were mild intermittent, mild persistent, moderate persistent and severe persistent based on the magnitude of severity which was based on day time and night time symptoms as well as PEF variability.

\section{RESULTS}

Table 1 and 2 show the information on age and anthropometric data of respondents. There was no significant difference in age, height, weight and BMI among respondents. PEF measurements were carried out before and after school on Monday, Wednesday and Friday. Results showed that the PEF after schools decreased in most of the measurement days among the respondents (Table 3). The comparison of PEF reading before and after school in 3 days showed a significant difference on Monday (Table 4). 
Am. J. Applied Sci., 9 (10): 1553-1560, 2012

Table 1: Asthma classification in adults and children

\begin{tabular}{lllll}
\hline Asthma classification & Daytime symptoms frequency & Nighttime symptoms frequency & PEFR/FEV1 (\%) & PEF variability $(\%)$ \\
\hline Mild Intermittent & $\leq 2 /$ week & $\leq 2 /$ month & $\geq 80$ & $<20$ \\
Mild persistent & $>$ 2/ week, but $<1 /$ day & $>2 /$ month & $\geq 80$ & $20-30$ \\
Moderate persistent & Daily & $>1 /$ week & $>60-<80$ & $<30$ \\
Severe persistent & Continual & Frequent & $\geq 60$ & $>30$ \\
\hline S
\end{tabular}

Source: National Heart, Lung and Blood Institute's (NHLBI, 2007)

Table 2: Information on anthropometric data among respondents

\begin{tabular}{|c|c|c|c|c|c|c|c|c|}
\hline \multirow[b]{2}{*}{ Variable } & \multicolumn{2}{|l|}{ Urban } & \multicolumn{2}{|l|}{ Industrial } & \multicolumn{2}{|l|}{ Rural } & \multirow[b]{2}{*}{$\mathrm{F}$} & \multirow[b]{2}{*}{$\mathrm{p}$} \\
\hline & Mean (SD) & Median (IQR) & Mean (SD) & Median (IQR) & Mean (SD) & Median (IQR) & & \\
\hline \multirow[t]{2}{*}{ Age (yr) } & 9.69 & 10.00 & 9.84 & 10.00 & 9.58 & 0.00 & 0.78 & 0.46 \\
\hline & -1.13 & -2.00 & -1.08 & -2.00 & -1.10 & -2.00 & & \\
\hline \multirow[t]{2}{*}{ Weight $(\mathrm{kg})$} & 32.51 & 29.20 & 33.16 & 31.20 & 29.40 & 28.00 & 2.90 & 0.06 \\
\hline & -10.17 & -18.40 & -9.43 & -14.60 & -5.76 & -6.40 & & \\
\hline \multirow[t]{2}{*}{ Height $(\mathrm{cm})$} & 131.25 & 132.00 & 134.30 & 132.90 & 130.67 & 132.00 & 2.92 & 0.06 \\
\hline & -10.01 & -16.70 & -8.68 & -13.80 & -10.01 & -16.70 & & \\
\hline \multirow[t]{2}{*}{ BMI } & 18.74 & 17.39 & 17.88 & 16.99 & 17.26 & 16.75 & 1.94 & 0.15 \\
\hline & $(4.66))$ & -5.26 & -4.54 & -5.40 & -2.85 & -3.24 & & \\
\hline
\end{tabular}

Table 3: Peak expiratory flow reading before and after school according to areas

\begin{tabular}{|c|c|c|c|c|c|c|}
\hline \multirow[b]{2}{*}{ Area/Day } & \multicolumn{2}{|l|}{ Monday } & \multicolumn{2}{|l|}{ Wednesday } & \multicolumn{2}{|l|}{ Friday } \\
\hline & $\begin{array}{l}\text { Before school } \\
\text { Mean (SD) }\end{array}$ & $\begin{array}{l}\text { After School } \\
\text { Mean (SD) }\end{array}$ & $\begin{array}{l}\text { Before school } \\
\text { Mean (SD) }\end{array}$ & $\begin{array}{l}\text { After School } \\
\text { Mean (SD) }\end{array}$ & $\begin{array}{l}\text { Before school } \\
\text { Mean (SD) }\end{array}$ & $\begin{array}{l}\text { After School } \\
\text { Mean (SD) }\end{array}$ \\
\hline Urban & $154.42(47.25)$ & 154.85 (46.96) & $151.08(29.56)$ & $145.17(28.70)$ & $154.83(33.93)$ & $152.83(33.68)$ \\
\hline Industrial & $148.75(39.81)$ & $140.68(38.70)$ & $158.58(36.79)$ & $151.02(36.53)$ & $156.36(39.84)$ & $153.47(38.85)$ \\
\hline Rural & $156.64(49.78)$ & $150.93(47.24)$ & $138.85(36.71)$ & $136.52(36.86)$ & $148.23(44.14)$ & $156.81(46.44)$ \\
\hline
\end{tabular}

Table 4: The comparison of PEF reading before and after school during the three days

\begin{tabular}{|c|c|c|c|c|}
\hline Day & Time & Mean (SD) & $\mathrm{t}$ & $\mathrm{p}$ \\
\hline \multirow[t]{2}{*}{ Monday } & Before school & 7.440 & 3.890 & $<0.001 * * *$ \\
\hline & After school & -21.990 & & \\
\hline \multirow[t]{2}{*}{ Wednesday } & Before school & 5.270 & 1.821 & 0.071 \\
\hline & After school & -33.230 & & \\
\hline \multirow[t]{2}{*}{ Friday } & Before school & -1.223 & -0.440 & 0.658 \\
\hline & After school & -31.650 & & \\
\hline
\end{tabular}

*** Significant at $\mathrm{p} \leq 0.001$

Table 5: The PEF variability among respondents in the three areas

\begin{tabular}{|c|c|c|c|}
\hline \multirow[b]{2}{*}{ Peak expiratory flow variability (\%) } & \multicolumn{3}{|l|}{ Area } \\
\hline & Urban $\mathrm{n}(\%)$ & Industrial n(\%) & Rural n(\%) \\
\hline Low & $38(43.68)$ & $31(58.40)$ & $22(41.51)$ \\
\hline Moderate & $36(41.38)$ & $22(41.51)$ & $23(43.30)$ \\
\hline High & 13 (14.94) & $14(20.80)$ & $8 \quad(15.09)$ \\
\hline
\end{tabular}

Table 6: Variables that influenced the Peak Expiratory Flow (PEF) reading after school among respondents

\begin{tabular}{lrrr}
\hline Variable & Mean Square & $\mathrm{F}$ & $\mathrm{p}$ \\
\hline Constant & 18814.26 & 36.27 & 0.001 \\
Subjects & 586.80 & 1.10 & 0.326 \\
Locations & 702.89 & 1.32 & 0.270 \\
Subjects*Location & 670.70 & 1.26 & 0.099 \\
Day in a week & 2759.73 & 5.17 & $0.006^{*}$ \\
Location*Day & 1123.43 & 2.11 & 0.081 \\
PEF before school & 137789.89 & 258.29 & $<0.001^{* * *}$ \\
\hline
\end{tabular}

$\mathrm{R}^{2}=0.789$; ***: Significant at $\mathrm{p} \leq 0.001$; *: Significant at $\mathrm{p} \leq 0.01 ; \mathrm{y}: 36.27+5.17$ (day) + 258.29 (PEF before) 
Am. J. Applied Sci., 9 (10): 1553-1560, 2012

Table 7: Classification on severity of asthma among respondents

\begin{tabular}{|c|c|c|c|c|}
\hline \multirow{2}{*}{$\frac{\text { Area }}{\text { Urban }}$} & \multicolumn{2}{|c|}{ Severity of asthma } & & $\mathrm{n}(\%)$ \\
\hline & \multicolumn{2}{|c|}{ Intermittent } & & $20(22.90)$ \\
\hline \multirow{3}{*}{ Urban } & \multicolumn{2}{|c|}{ Mild persistent } & & $43(49.43)$ \\
\hline & \multicolumn{2}{|c|}{ Moderate persistent } & & $22(25.28)$ \\
\hline & \multicolumn{2}{|c|}{ Severe persistent } & & $2(2.29)$ \\
\hline \multirow[t]{4}{*}{ Industrial } & \multicolumn{2}{|c|}{ Intermittent } & & $18(26.87)$ \\
\hline & \multicolumn{2}{|c|}{ Mild persistent } & & $30(44.78)$ \\
\hline & \multicolumn{2}{|c|}{ Moderate persistent } & & $18(26.86)$ \\
\hline & \multicolumn{2}{|c|}{ Severe persistent } & & $1(1.49)$ \\
\hline \multirow[t]{4}{*}{ Rural } & \multicolumn{2}{|c|}{ Intermittent } & & $9(16.98)$ \\
\hline & \multicolumn{2}{|c|}{ Mild persistent } & & $36(67.92)$ \\
\hline & \multicolumn{2}{|c|}{ Moderate persistent } & & $7(13.21)$ \\
\hline & \multicolumn{2}{|c|}{ Severe persistent } & & $1(1.89)$ \\
\hline \multicolumn{2}{|l|}{ Risk factor } & OR & $(95 \% \mathrm{CI})$ & $\mathrm{p}$ \\
\hline \multirow[t]{3}{*}{ Location of study } & Rural & 1.000 & - & \\
\hline & Urban & 2.583 & $1.163-5.736$ & $0.022 *$ \\
\hline & Industrial & 2.180 & $0.931-5.106$ & 0.735 \\
\hline \multirow[t]{3}{*}{ Location of house to the main road } & $<1000 \mathrm{~m}$ & 1.000 & - & \\
\hline & $500-1000 \mathrm{~m}$ & 1.607 & $0.03-3.30$ & 0.299 \\
\hline & $100-500 \mathrm{~m}$ & 1.823 & $0.85-6.56$ & 0.232 \\
\hline $\mathbf{P M}_{10}$ & & 1.021 & $1.001-1.041$ & $0.040^{*}$ \\
\hline \multicolumn{5}{|l|}{ Allergy reaction } \\
\hline \multirow[t]{2}{*}{ Allergic to pollen } & No & 1.000 & - & \\
\hline & Yes & 2.392 & $1.301-4.39$ & $0.010^{*}$ \\
\hline \multirow[t]{2}{*}{ Allergic to food } & No & 1.000 & - & \\
\hline & Yes & 2.109 & $1.159-3.836$ & $0.015^{*}$ \\
\hline \multirow[t]{2}{*}{ Allergic to mold objects } & No & 1.000 & - & \\
\hline & Yes & 2.234 & $1.256-4.228$ & $0.007 *$ \\
\hline \multicolumn{5}{|l|}{ Family } \\
\hline \multirow[t]{2}{*}{ Father's education } & Low & 1.000 & - & \\
\hline & High & 0.477 & $0.243-0.937$ & $0.032 *$ \\
\hline \multirow[t]{2}{*}{ Father's asthma } & No & 1.000 & & \\
\hline & Yes & 1.138 & $0.579-2.236$ & 0.708 \\
\hline \multirow[t]{2}{*}{ Mother's asthma } & No & 1.000 & & \\
\hline & Yes & 1.214 & $0.624-2.359$ & 0.568 \\
\hline
\end{tabular}

* Significant at $\mathrm{p} \leq 0.05$; Logistic regression analysis using Enter method after adjusting for age and gender

Table 9: Variables associated with severity of asthma among respondents

\begin{tabular}{lllll}
\hline Risk factors & $\beta$ & $(95 \% \mathrm{CI})$ & $\mathrm{OR}$ & $\mathrm{P}$ \\
\hline Constant & -1.536 & - & 0.215 & 0 \\
Allergic to pollen & 0.696 & $1.100-3.656$ & 2.005 & $0.023^{*}$ \\
$\mathrm{PM}_{10}$ & 0.753 & $1.002-4.502$ & 2.124 & $0.049^{*}$ \\
\hline
\end{tabular}

Logistic regression using backward stepwise method; *: Significant at $\mathrm{p} \leq 0.05 ; \mathrm{N}=207$; OR significant $>1$ at $95 \% \mathrm{CI}$; Log (Severity of asthma $)=0.696($ Allergic to pollen $)+0.753\left(\mathrm{PM}_{10}\right)-1.53$

Table 5 shows the PEF variability among respondents. Results showed that the industrial children had high PEF reading variability, with more than $30 \%$ variability, followed by the urban children. For moderate PEF variability, it was $20-30 \%$ and for low PEF variability, it was less than $20 \%$.

Table 6 shows the PEF reading after schoolamong the respondents with respect to location, day and time. General linear model statistics were used to obtain the model for dependent variable such as the PEF reading after school. Results showed significant influence of specific day and PEF reading before school on the PEF reading after school for respondents in the 3 areas.

Table 7 shows the classification of severity of asthma among respondents. The classification was carried out through the PEF variables calculation, day and night symptoms as well as the respiratory scores. Results showed that most of the children had mild and moderate asthma. However, there were 2 cases in the urban area and 1 case in the industrial area were with severe asthma.

Table 8 and 9 show the variables associated with severity of asthma among respondents. From the logistic regression model, variables which significantly influenced the severity of asthma were $\mathrm{PM}_{10}$ and fathers' education. The equations obtained showed an increase in the severity of asthma with the increase of allergy to pollen (0.696) and exposure to $\mathrm{PM}_{10}(0.753)$. 
Am. J. Applied Sci., 9 (10): 1553-1560, 2012

\section{DISCUSSION}

Information on the socio-demographic and economic status of the respondents was obtained from self administered questionnaires. The questionnaires were completed by the parents. The questionnaires were adapted from the International Study of Asthma and Allergies in Childhood (ISAAC).

Inclusion criteria were considered during the selection of respondents. Inclusion criteria include children diagnosed with asthma, aged 8 to 11 years old, studying in the selected schools, Malaysian citizen and without other chronic diseases such as bronchitis, heart problem, leukemia and had not undergone surgery.

From the anthropometric data, there was no significant difference in the age and body mass index among respondents. Statistics showed a significant difference in the parents' education years among the study groups. Parents from urban area had better education compared to industrial and rural areas in which the majority have only Malaysian Certificate of Education (MCE).

PEF reading was taken by using peak expiratory flow meter Model Mini Weight AFS CE 0120. Results showed significant difference in peak expiratory flow reading among respondents before and after school hours in most of the days. PEF readings after school were lower than the PEF before school.This can be best explained by the children's exposure to outdoor air pollutants when they were in school. Distance of schools from roads and highway were the main factors which contributed to high level of air pollution within the school area. Study conducted by Janssen et al. (2003), showed that air pollution concentrations in and outside of schools located on different parts of the main road were significantly associated with their distance.

However, conclusion cannot be made that the PEF decrement was due to the air pollution itself, since there were other variables which might influence the readings. Besides these, specificity and reliability of the readings taken should also be considered. With reference to Lambert et al. (2004), repeated measures in individual measurements was possible to reduce the effects between subjects, within subjects variation and within day variations. Repeated measures of PEF readings as many as 6 times were obtained from respondents during the 3 days measurements, before and after school.

To study the association between PEF after school with days, location and time, General Linear Model (GLM) statistics were used to get the model for PEF reading after school as a dependent variable. Results showed significant influence of specific days and PEF readings before school, on the PEF reading after school in the 3 areas. Peak expiratory flow can be used to define and assess the severity of asthma which were usually recorded for two weeks period with two or more measurements in one day (Pérez-Yarza et al., 2006; Patel et al., 2005; Klein et al., 1995). Study by Timonen et al. (1997), among asthmatic children, found that the morning PEF decreased by 0.27 and $0.31 \%$ in urban area and suburban area, respectively, with the 10 $\mu \mathrm{g} \mathrm{m}^{-3}$ increase of $\mathrm{PM}_{10}$ in the daily mean.

Statistics showed that the effects of days were shown to be significantly influenced by the PEF reading after school. Even though, this research did not study on the correlation between changes in PEF differences with daily concentrations of air pollutant, results of this showed the effects of day on the PEF. This finding might be explained by the fact that the airways of asthmatic children were susceptible to the ambient air variability. Dockery and Pope (1994), estimated that the mean increase of $3 \%$ in the prevalence of lower respiratory symptoms were associated with 10 $\mu \mathrm{g} / \mathrm{m}^{3}$ increase in daily $\mathrm{PM}_{10}$ concentrations. Besides this, Lawther et al. (1974) found that there was a consistent relationship between day to day ventilatory functions with the environmental pollutants among respondents.

The daily variations in the increase of ambient air pollution concentrations of black smoke, $\mathrm{PM}_{10}$, NO and $\mathrm{CO}$ were consistently associated with impairment of baseline lung functions. The reductions in Force Vital Capacity (FVC) and Forced Expiratory Volume in $1 \mathrm{sec}$ $\left(\mathrm{FEV}_{1}\right)$ were 0.5 and $0.6 \%$, respectively, for each $10 \mu \mathrm{g}$ $\mathrm{m}^{-3}$ increase in black smoke. Particles derived from combustion affect baseline lung functions rather than bronchial responsiveness among children with chronic respiratory symptoms (Timonen et al., 2002).

$\mathrm{PEF}$ is the maximum flow generated at any time during a forced exhalation and usually occurs in the first 150 milliseconds of a forced expiratory. Sometimes PEF variability claimed to be the expression of bronchial hyper-responsiveness, when the variability is being calculated as the difference between maximum PEF and minimum PEF (Vargas et al., 2005). However, PEF variability can therefore, not replace bronchial challenge tests to determine the presence of bronchial hyper-responsiveness, as it does not measure the same aspects as the bronchial challenge test (Lebowitz, 1996). According to Pérez-Yarza et al. (2006), $\mathrm{FEV}_{1}$ is the most suitable lung function parameter for the classification of asthma severity in children. The classification of the severity of asthma among respondents was recommended by the National Heart, Lung and Blood Institute's (NHLBI) National Asthma Education and Prevention Program (NAEPP) Expert 
Am. J. Applied Sci., 9 (10): 1553-1560, 2012

Panel Report 2. These guidelines placed a major emphasis on diagnosis, management and approach to asthma treatment. In this study the classification of severity of asthma was adapted from this guideline with a few modifications. The main focus was on the classification of the severity of asthma.

Factors which were taken into account for the classification were day time symptoms, night time symptoms and PEF variability. Day and night symptoms were obtained from the questionnaire. For PEF variability, it was computed using a formula.

The importance of asthma classification was due to the management and control of the disease. For example, higher doses of inhaled corticosteroids were prescribed to patients with more severe asthma conditions (Khotija, 2008). Results showed most of the children had mild and moderate asthma. There were 2 cases in the urban area with severe asthma. Risk factor is defined as the potential factors which may cause or develop more severe stage of the disease. Asthma is actual fact, involved multi-factors in developing its severity. The interaction between numerous environmental factors and the genetic predisposition makes asthma a complex disease in which the effect of a single genetic or environmental factor may be difficult to detect or evaluate.

Air pollution is a major environmental risk to health and is estimated to cause approximately 2 million premature deaths worldwide per year WHO, 2010. From the binary logistic regressions, factors which significantly influenced the severity of asthma among respondents were the ambient $\mathrm{PM}_{10}$ and allergy to pollen.

Study conducted by Jamal et al. (2004) on exposure to $\mathrm{NO}_{2}$ had the potential impact of asthma exacerbation, upper respiratory tract infection (URTI) which could lead to hospital admission. Increment in $\mathrm{PM}_{10}$ level as low as $10 \mathrm{mg} / \mathrm{m}^{3}$ showed an effect in the form of increase of hospital admission for asthma and other respiratory diseases. In addition, exposure to $\mathrm{PM}_{10}$ among adults with cardiovascular problem increased hospital admissions.

Particulate matter is the component of air pollution which is responsible for many adverse health effects to human health and several studies have shown a positive association between overall daily morbidity and ambient particle concentrations (Boldo et al., 2006; Kim et al., 2006). In Malaysia, number of studies conducted locally showed that air pollutants can worsen childhood asthma even at a low concentration (Jamal et al., 2004; Zailina et al., 1997; 1996; 2004; Abdul et al., 2003). It was estimated that $18 \%$ of world's urban areas have ambient air containing an amount mean of over $100 \mu \mathrm{g} / \mathrm{m}^{3}$ of $\mathrm{PM}_{10}$ (Cohen et al., 2005).
This study had shown a significant association between $\mathrm{PM}_{10}$ concentration and asthma severity among respondents. This finding was supported by another research by Abdul et al. (2003) who concluded that $\mathrm{PM}_{10}$ affected exposed children's respiratory system in term of lung functions abnormality and also increased their respiratory symptoms. Local study conducted by Junaidah et al. (2010) found that there was an association between the prevalence of respiratory and allergy symptoms with locations. Urban children have more count of symptoms of difficulty in breathing, chest tightness and wheezing.

The major sources of $\mathrm{PM}_{10}$ in urban and industrial areas were the heavy traffic and vehicle fossil fuel combustion which generate particulate matter and other gases. In this situation, the process of nucleation and coagulation could trigger the formation of $\mathrm{PM}_{10}$. Therefore, heavy traffic high polluted area especially during rush hour early in the morning and afternoon would fabricate more $\mathrm{PM}_{10}$ as the movement of vehicle will disperse the particles that sink on the ground or vegetation at night. So, the particles are constantly being pushed upward into the air and with no ambient stability in the sampling sites helped particles deposition.

Fine and coarse particles differ in term of the emission sources, formation process, chemical composition, transport distance and other parameters. Fine particles are directly emitted from combustion sources and also formed secondarily from gaseous precursors, for example, SO2, NOx or organic compounds. Commonly, fine particles composed of sulfate, nitrate, chloride and ammonium compounds, organic and elemental carbon and metals. In addition, combustion of coal, oil, diesel, gasoline, wood and industrial process sources can produce emissions that contribute to ambient fine particle concentration. On the other hand, the coarse particles are mechanically generated at outdoors by crushing, construction, grinding operations, farming and mining activities. Most coarse particles typically deposited to earth within minutes to hours and within ten kilometers from the emission sources (Rom, 2007). Study by Stallberg et al. (2007) report that one of the contributing factor associated with asthma severity is allergic to pollen. Subsequently, study conducted by Jianan et al. (2007) illustrated that the pollination in develop urban areas is higher than in undeveloped rural areas. Thus urban and industrial area had a greater amount of pollen in the air as compared to rural area. Apart from that, allergy to pollen is common among asthmatic and allergy sensitization is associated with increased frequency of emergency visits (Pollart et al., 1987). 


\section{CONCLUSION}

In conclusion, this study demonstrated that pollutants are an important factor associated with severity in asthma among children. The lack of other diagnosis data to determine the severity of asthma among respondents in our study should, however, be addressed in future studies to confirm our conclusions about asthma severity.

\section{ACKNOWLEDGEMENT}

This study was supported by grants from the Research University Grant Scheme of Universiti Putra Malaysia. We acknowledge all participating schools, teachers, children and parents for their cooperation during the study.

\section{REFERENCES}

Abdul, M.A., H. Zailina, J. Juliana and M.T.S. Bahri, 2003. Partikel ternafas $\left(\mathrm{PM}_{10}\right)$ dan hubungannya dengan sistem respiratori di kalangan kanak-kanak sekolah di Sungai Siput Utara, Perak. Malaysian J. Public Health Med., 3: 23-32.

Boldo, E., S. Medina, A. LeTertre, F. Hurley and H.G. Mucke et al., 2006. Apheis: Health impact assessment of long-term exposure to $\mathrm{PM}(2.5)$ in 23 European cities. Eur. J. Epidemiol. 21: 449-458. PMID: 16826453

Bosquet, J., P.K. Jeffery, W.K. Busses, M. Johnson and A.M. Vignola, 2000. Asthma. From bronchoconstriction to airways inflammation and remodeling. Am. J. Respiratory Critical Care Med., 161: 1720-1745. PMID: 10806180

Cohen, A.J., H. Ross-Alexander, B. Ostro, K.D. Pandey and M. Kryzanowski et al., 2005. The global burden of disease due to outdoor air pollution. J. Toxicol. Environ. Health, 68: 1301-1307. PMID: 16024504

Dockery, D.W. and C.A. Pope, 1994. Acute respiratory effects of particulate air pollution. Annual Rev. Public Health, 15: 107-132. DOI: 10.1146/annurev.pu.15.050194.000543

Haitchi, H.M., M.T. Krishna, J.H. Holloway, G. Dent and M.G. Buckley et al., 2004. Asthma: Clinical Aspects and Mucosal Immunology. In: Medical Immunology, Mestteky, J., M.E. Lamin, W. Scrobor, J. Bienenstock and J.R. McGhee et al. (Eds.). Academic Press, UK, pp: 1415-1432.

Jamal, H.H., S.P. Mukundan, H. Zailina, S.S. Bahari and S. Kazal et al., 2004. A Study of Health Impact and Risk Assessment of Urban Air Pollution in the Klang Valley. UKM Pakarunding Sdn Bhd., Kuala Lumpur, Malaysia.
Janssen, N.A., B. Brunekreef, P. Van-Vliet, F. Aarts and K. Meliefste et al., 2003. The relationship between air pollution from heavy traffic and allergic sensitization, bronchial hyperresponsiveness and respiratory symptoms in Dutch schoolchildren. Environ Health Perspect., 111: 1512-1518.

Jianan, X., O. Zhiyun, Z. Hua, W. Xiaoke and M. Hong, 2007. Allergenic pollen plants and their influential factors in urban areas. Acta Ecol. Sinica, 27: $\quad 3820-3827$. DOI: $10.1016 / S 1872-$ 2032(07)60082-1

Junaidah, Z., H. Zailina, M.S. Lye and H.H. Jamal, 2010. Allergy to air pollution and frequency of asthmatic attack s among asthmatic primary school children. Am. Eurasian J. Toxicol. Sci., 2: 83-92.

Khotija, R., 2008. Classifying asthma severity and treatment determinants: National guidelines revisited . Malaysian Family Physician, 3: 131-136.

Kim, Y.J., K.W. Kim, S.D. Kim, B.K. Lee and J.S. Han, 2006. Fine particulate matter characteristics and its impact on visibility impairment at two urban sites in Korea: Seoul and Incheon. Atmospheric Environ., 40: 593-605. DOI: 10.1016/j.atmosenv.2005.11.076

Klein, R.B., G.K. Fritz, A. Yeung, E.L. McQuide and A. Mansell, 1995. Spirometric patterns in childhood asthma: Peak flow compared with other indices. Pediatric Pulmonol., 20: 372-379. PMID: 8649917

Lambert, P.C., P.R. Burton, K.R. Abrams and A.M. Brooke, 2004. The analysis of peak expiratory flow data using a three-level hierarchical model. Stat. Med., 23: 3821-3839. PMID: 15580603

Lawther, P.J., A.G. Brooks, P.W. Lord and R.E. Waller, 1974. Day-to-day changes in ventilatory function in relation to the environment. Environ. Res., 8: 119-130. PMID: 4477063

Lebowitz, M.D., 1996. Epidemiological studies of the respiratory effects of air pollution. Eur. Respir. J., 9: 1029-1054. PMID: 8793468

Nasir, M.H., W.Y. Choo, A. Rafia, M.R. Md and L.C. Theng et al., 2000. Estimation of health damage cost for 1997-haze episode in malaysia using the ostro model. Proceedings of the Malaysians Science and Technology Congress, Confederation of Scientific and Technological Association in Malaysia (COST-AM), Kuala Lumpur, in Press.

Norzila, M.Z., A.L. Haifa, C.T. Deng and B.H. Azizi, 2000. Prevalence of childhood asthma and allergy in an inner city Malaysian community: Intraobserver reliability of two translated international questionnaires. Med. J. Malaysia, 55: 33-39. PMID: 11072488 
Omar, A.H., 1990. Respiratory symptoms and asthma in primary school children in Kuala Lumpur. Acta Paediatr Jap., 32: 183-187. PMID: 2116069

Patel, D., A. Eley, S. Offutt and E. Bader, 2005. Peak inspiratory and expiratory flow meter. University of Wisconsin, Madison.

Pérez-Yarza, E.G., N. Cobos, J.J.D.L. Cruz, 2006. Variability in peak expiratory flow does not classify asthma according to severity. Archive Bronconeumol., 43: 535-541. DOI: 10.1016/S1579-2129(07)60124-4

Pollart, S.M., M.D. Chapman and T.A. Platts-Mills, 1987. Chapman and T.A. Platts-Mills. House dust sensitivity and environmental control. Prim Care., 14: 591-603. PMID: 3313464

Rafia, R., N.H. Mohd and I.N. Akma, 2003. Review of air pollution and health impacts in Malaysia. Environ. Res., 92: 71-77. DOI: 10.1016/S00139351(02)00059-2

Stallberg, B., K. Lisspers, M. Hassalgren, G. Johansson and K. Svardsudd, 2007. Factors related to the level of severity of asthma in primary care. Respir. Med., 101: 2076-2083. PMID: 17628463

Rom, W.N., 2007. Environmental and Occupational Medicine. 4th Edn., Lippincott Williams and Wilkins, Philadelphia, ISBN-10: 0781762995, pp: 1904.

Timonen, K.L. and P. Juha, 1997. Air pollution and respiratory health among children with asthmatic or cough symptoms. Am. J. Respiratory Critical Care Med., 156: 546-552. PMID: 9279238
Timonen, K.L. J. Pekkanen, P. Tiittanen and R.O. Salonen, 2002. Effects of air pollution on changes in lung function induced by exercise in children with chronic respiratory symptoms. Occup. Environ. Med., 59: 129-134. PMID: 11850557

Vargas, M.H., H.H. Ruiz-Gutierrez, C. EspinosaSerafin, G. Zuniga-Vazquez and M.E. Furuya, 2005. Underestimation of the peak flow variability in asthmatic children: Evaluation of a new formula. Pediatric Pulmonol., 39: 325-331. PMID: 15704185

Johnston, S.L. and S.T. Holgate, 2008. Asthma: Critical Debates. 1st Edn., Blackwell Science, London, ISBN-10: 047069310X, pp: 408.

Zailina, H., J. Juliana and H.H. Jamal, 2004. Comparison of lung functions among asthmatic children in Malaysia. Pertanika J. Sci. Technol., 12: 11-20.

Zailina, H., J. Juliana, M.Z. Norzila, H.O. Azizi and H.H. Jamal, 1997. The relationship between kuala lumpur haze asthmatic attacks in children. Malaysian J. Child. Health, 9: 151-159.

Zailina, H., J. Juliana, Z.A. Azman and H.O. Azizi, 1996. The associations of $\mathrm{PM}_{10}$ and asthmatic patient. Pertanika J. Sci. Technol., 4: 275-282. 